\title{
Calendar of Events for Vol.6-issue 4, 2012
}

\section{EPOS "BAT_Educational Programme"}

Basic Course I

12th-14th september, 2012

Vienna, Austria

For further information: http://www.efort.org/education/

EPOS "BAT_Educational Programme"

Traumatology

13th-15th march, 2013

Vienna, Austria

For further information: http://www.efort.org/education/
EPOS 32nd annual meeting, Athens 2013

17th-20th April, 2013

Athens, Greece

For further information: http://www.epos2013.gr.

Contact: info@epos2013.gr

EPOS "BAT_Educational Programme"

Basic Course II

9th-11th October, 2013

Vienna, Austria

For further information: http://www.efort.org/education/ 